\title{
Efeito da Deriva Simulada de Glyphosate no CRescimento Inicial de Plantas de Pinhão-Manso ${ }^{1}$
}

\author{
Effect of Simulated Glyphosate Drift on the Initial Growth of Physic Nut Plants
}

COSTA, N.V.. ${ }^{2}$ ERASMO, E.A.L. ${ }^{3}$, QUEIROZ, P.A. ${ }^{4}$, DORNELAS, D.F. ${ }^{4}$ e DORNELAS, B.F. ${ }^{4}$

\begin{abstract}
RESUMO - Objetivou-se avaliar o efeito da deriva simulada do herbicida glyphosate no crescimento inicial de plantas de pinhão-manso (Jatropha curcas) em casa de vegetação. Para simulação da deriva de glyphosate, utilizaram-se as seguintes doses: 0,$0 ; 1,4 ; 2,8 ; 5,6 ; 11,3$; 22,5; 45,0; 90,0; 180,0; e 360,0 $\mathrm{g}_{\text {ha }}{ }^{-1}$ de glyphosate, distribuídas em blocos casualizados, com quatro repetições. O glyphosate foi aplicado 51 dias após a semeadura, quando as plantas de pinhão-manso apresentavam entre 16 e 18 folhas completamente desenvolvidas e altura média de $45 \mathrm{~cm}$. As aplicações das doses foram feitas com pulverizador costal pressurizado a $\mathrm{CO}_{2}$, regulado para proporcionar $200 \mathrm{~L} \mathrm{ha}^{-1}$. Os resultados indicam que a altura, o diâmetro do caule, a área foliar, bem como a massa seca de folha, caule e raiz das plantas de pinhãomanso, apresentaram reduções após a simulação da deriva de glyphosate, em relação à testemunha. Dessa forma, pode-se concluir que o desenvolvimento inicial das plantas de pinhão-manso foi influenciado pela deriva simulada de glyphosate; a deriva de doses superiores a 45,0 $\mathrm{g} \mathrm{ha}^{-1}$ pode ser severamente prejudicial às plantas no periodo de 41 dias após a aplicação.
\end{abstract}

Palavras-chave: Jatropha curcas, planta daninha, tecnologia de aplicação, herbicidas.

\begin{abstract}
This work aimed to evaluate the effect of simulated glyphosate drift on the initial growth of physic nut plants (Jatropha curcas) under greenhouse conditions. The experimental design was a randomized block with four replications. To simulate drift, glyphosate was used at the following rates: 0.0, 1.4, 2.8, 5.6, 11.3, 22.5, 45.0, 90.0, 180.0 and $360.0 \mathrm{~g} \mathrm{ha}^{-1}$, distributed in randomized blocks with four replications. Glyphosate was applied 51 days after sowing, when the plants displayed between 16 and 18 fully developed leaves and $45 \mathrm{~cm}$ height. A backpack sprayer was used, pressurized to $\mathrm{CO}_{2}$ and adjusted to provide spraying consumption of $200 \mathrm{~L} \mathrm{ha}{ }^{-1}$. The results indicated that height, stem diameter, leaf area and dry mass of leaf, stem and root of the physic nut plants showed reductions after glyphosate drift simulation, compared with the control. Thus, it can be concluded that the initial growth of the physic nut plants was influenced by simulated glyphosate drift, and that the drift of rates higher than $45.0 \mathrm{~g} \mathrm{hal}$ can cause severe damage to the plants during the period of 41 days after application.
\end{abstract}

Keywords: Jatropha curcas, weed, application technology, herbicides.

\section{INTRODUÇÃO}

Estudos referentes à utilização de óleos vegetais como matéria-prima para produção de combustivel para motores a diesel estão aumentando mundialmente, principalmente por ser fonte renovável de energia. Assim, diante das tendências agroenergéticas, o Brasil destaca-se por possuir áreas disponíveis para a produção em grande escala, além de espécies nativas com potencial para a produção de biocombustivel - a exemplo do pinhão-manso (Jatropha curcas) (Teixeira, 2005).

1 Recebido para publicação em 4.4.2009 e na forma revisada em 11.12.2009.

2 Doutor em Agronomia/Agricultura, Bolsista “DCR - FUNDEG-FAG/SECT-TO" < neumarciovc@hotmail.com>; ${ }^{3}$ Prof. Adjunto da Universidade Federal do Tocantins - UFT, Rua Badejós, chácaras 69 e 72 Lt.07, Zona Rural, Caixa Postal 66, $77404-970$ campus de Gurupi-TO; ${ }^{4}$ Graduando de Agronomia, UFT, campus de Gurupi-TO. 
O pinhão-manso, pertencente à família Euphorbiaceae, é uma planta perene, rústica e adaptada às mais diversas condições edafoclimáticas. Caracteriza-se por ser um arbusto que pode atingir até $5 \mathrm{~m}$ de altura e apresenta folha decídua, pecíolo grande e esverdeado, caule liso e cilindrico, fruto carnudo tipo cápsula trilocular, com três sementes. Por apresentar ciclo reprodutivo bastante prolongado, a planta pode chegar a 40 anos, com média de produtividade de 2,0 t ha ${ }^{-1}$ de sementes (Purcino \& Drummond, 1986; Arruda et al., 2004; Saturnino et al., 2005).

Devido ao interesse recente pela exploração do pinhão-manso como cultura oleaginosa, existem atualmente poucas informações sobre as recomendações técnicas de manejo, principalmente as referentes ao controle de plantas daninhas. Dessa maneira, semelhante a outras culturas perenes, a interferência das plantas daninhas no período inicial de desenvolvimento das plantas de pinhão-manso pode comprometer o crescimento e o desenvolvimento vegetativo, bem como a quantidade e a qualidade do óleo das sementes. Entre os métodos de controle das plantas daninhas, a utilização de herbicidas não seletivos aplicados de forma dirigida na linha de plantio pode apresentar-se como excelente alternativa, considerando principalmente o controle dessas espécies em extensas áreas de plantio, a exemplo do que é utilizado em culturas como eucalipto, pínus e de várias frutíferas (Rodrigues \& Almeida, 2005; Santos et al., 2006; Gravena et al., 2009).

Apesar de não haver ainda herbicidas registrados para a cultura do pinhão-manso no Brasil, o glyphosate vem sendo utilizado em áreas de plantio comercial de pinhão-manso. Assim, a realização de estudos referentes à biossegurança do glyphosate, como os de deriva simulada, é necessária para subsidiar um futuro registro desse herbicida para a cultura.

Entre as áreas de plantio comercial, destaca-se a da Fazenda Bacaba, localizada no município de Caseara, no Estado do Tocantins, onde atualmente existem 3 mil hectares com a cultura e com perspectiva de ampliação da área de plantio (comunicação pessoal). A opção pelo uso do glyphosate na cultura do pinhãomanso baseou-se em suas características de herbicida de ação sistêmica, não seletivo, amplo espectro de controle de plantas daninhas, fácil adsorção pelos coloides do solo, além do baixo custo em relação a outros herbicidas (Rodrigues \& Almeida, 2005).

Ressalta-se que, em áreas onde o controle químico é frequentemente utilizado, têm-se observado problemas de intoxicação em espécies não alvo, decorrente da deriva produzida durante a aplicação. Dessa forma, em aplicações dirigidas de produtos não seletivos, como no caso dos herbicidas à base de glyphosate, a própria cultura pode ser afetada pelo contato com o herbicida, podendo causar intoxicação, alterações morfoanatômicas do limbo foliar, queda da resistência a ataque de doenças fúngicas, deficiência nutricional, redução no crescimento e até a morte das plantas (Rizzardi et al., 2003; Yamashita \& Guimarães, 2005; Santos et al., 2005, 2006, 2007a, b, 2008; Powell \& Swanton, 2008; Wagner Júnior et al., 2008).

Particularmente para a cultura do pinhãomanso, são escassas as informações referentes ao efeito fitotóxico das formulações à base de glyphosate disponiveis no mercado, bem como quanto aos niveis de tolerância da espécie a esse herbicida.

Os danos causados pela deriva do herbicida dependem da concentração e da quantidade do princípio ativo que chega às culturas (Santos et al., 2007b). Apesar dos prejuízos que a deriva de herbicidas pode proporcionar à produção agrícola, alguns pesquisadores constataram efeito estimulatório no crescimento de diversas espécies após a aplicação de subdoses de glyphosate (Santos et al., 2006; Cedergreen, 2008; Velini et al., 2008). Dessa maneira, objetivou-se com o presente trabalho avaliar o efeito da deriva simulada do herbicida glyphosate no crescimento inicial de plantas de pinhão-manso.

\section{MATERIAL E MÉTODOS}

O experimento foi instalado e conduzido na Universidade Federal do Tocantins, campus de Gurupi (TO), em casa de vegetação. Os tratamentos foram dispostos em blocos casualizados, com quatro repetições.

As amostras de solo utilizadas nos vasos apresentaram 669, 38 e $293 \mathrm{~g} \mathrm{~kg}^{-1}$ de areia, 
silte e argila, respectivamente. Os resultados da análise química evidenciaram $\mathrm{pH}$ em $\mathrm{CaCl}_{2}$ de 5,2; teor de matéria orgânica de $3,0 \mathrm{~g} \mathrm{dm}^{-3}$; CTC de 5,41 e P de 0,60 $\mathrm{mg} \mathrm{dm}^{-3}$; valores de $0,06,1,65,0,47$ e $0,08 \mathrm{cmol}_{\mathrm{c}} \mathrm{dm}^{-3}$ para $\mathrm{K}, \mathrm{Ca}$, $\mathrm{Mg}$ e Al, respectivamente; e saturação por bases de 40,3\%.

Em cada vaso foi utilizada adubação de base com $52 \mathrm{~g}$ do formulado 5-25-15, mais $0,04 \%$ de zinco, além de $4,1 \mathrm{~g}$ de $\mathrm{CaCO}_{3}$ para elevar a saturação por bases do solo a $60 \%$. Antes da semeadura, o solo permaneceu em sacos plásticos por um período de incubação de aproximadamente 15 dias.

As sementes foram provenientes da área de produção da Fazenda Bacaba, localizada na Rodovia TO-080, Km 99, entre os municipios de Marianópolis e Caseara (TO), pertencente ao grupo SAUDIBRAS - Agropecuário e Empreendimento e Representações Ltda. Foram utilizados vasos plásticos de sete litros de capacidade, sendo semeadas quatro sementes de pinhão-manso por vaso em 12/10/2008. Sete dias após a emergência, foi realizado o desbaste, permanecendo apenas uma planta por vaso. Aos 42 dias após a semeadura (DAS), foram aplicados $11,6 \mathrm{~g}$ de ureia por vaso, como adubação de cobertura.

O glyphosate (Atanor $360 \mathrm{~g} \mathrm{~L}^{-1}$ ) foi aplicado aos 51 DAS, quando as plantas de pinhãomanso apresentavam entre 16 e 18 folhas completamente desenvolvidas e altura média de $45 \mathrm{~cm}$, nas seguintes doses: 0,$0 ; 1,4 ; 2,8$; 5,$6 ; 11,3 ; 22,5 ; 45,0 ; 90,0 ; 180,0 ;$ e 360,0 g ha $^{-1}$ do equivalente ácido.

As aplicações do herbicida foram feitas com auxílio de um pulverizador costal, pressurizado a $\mathrm{CO}_{2}$ e equipado com barra de quatro pontas de jato plano (Teejet XR11002 VS), distanciadas $50 \mathrm{~cm}$ entre si e com um reservatório de dois litros, regulado para proporcionar um consumo de $200 \mathrm{~L} \mathrm{ha}^{-1}$ de calda.

No momento da aplicação, as médias de temperatura, umidade relativa do ar e velocidade do vento foram de $29,7^{\circ} \mathrm{C}, 72,0 \%$ e $0,5 \mathrm{~m} \mathrm{~s}^{-1}$, respectivamente.

As avaliações de intoxicação das plantas de pinhão-manso foram realizadas aos 7, $21 \mathrm{e}$ 41 dias após a aplicação dos tratamentos (DAA). Para isso, utilizou-se a escala percentual de notas visuais, em que 0 (zero) corresponde a nenhuma injúria na planta e 100 (cem) à morte das plantas (SBCPD, 1995). Os parâmetros utilizados no estabelecimento das notas foram: inibição do crescimento, quantidade e uniformidade das injúrias, capacidade de rebrota das plantas e quantidade de plantas mortas.

No final do experimento (41 DAA), foram avaliadas as seguintes variáveis nas plantas de pinhão-manso: altura da planta $(\mathrm{cm})$, mensurada entre o colo da planta e a folha mais alta; diâmetro do caule $(\mathrm{cm})$, a 1,0 cm do solo; número de ramos por planta; e massa seca de folha, caule, raiz e da planta inteira (Total). Determinou-se também a área foliar $\left(\mathrm{cm}^{2}\right)$, utilizando a fórmula $\mathrm{AF}=0,84[\mathrm{CxL}]^{0,99}$, proposta por Severino et al. (2007), em que: $\mathrm{C}=$ comprimento da região central do limbo foliar e $\mathrm{L}=$ largura da região mais extensa do limbo foliar.

Os resultados foram submetidos à análise de variância e regressão $(p>0,05)$.

\section{RESULTADOS E DISCUSSÃO}

O glyphosate proporcionou sintomas de intoxicação nas plantas de pinhão-manso aos 7 DAA somente a partir da dose de $11,3 \mathrm{~g} \mathrm{ha}^{-1}$, ao passo que as doses de 90,0, 180,0 e $360,0 \mathrm{~g} \mathrm{ha}^{-1}$ promoveram as maiores médias, na ordem de $9,8,11,3$ e $21,0 \%$, respectivamente (Figura 1). Os sintomas de intoxicação observados corresponderam a amarelecimento intenso a partir das folhas imaturas do

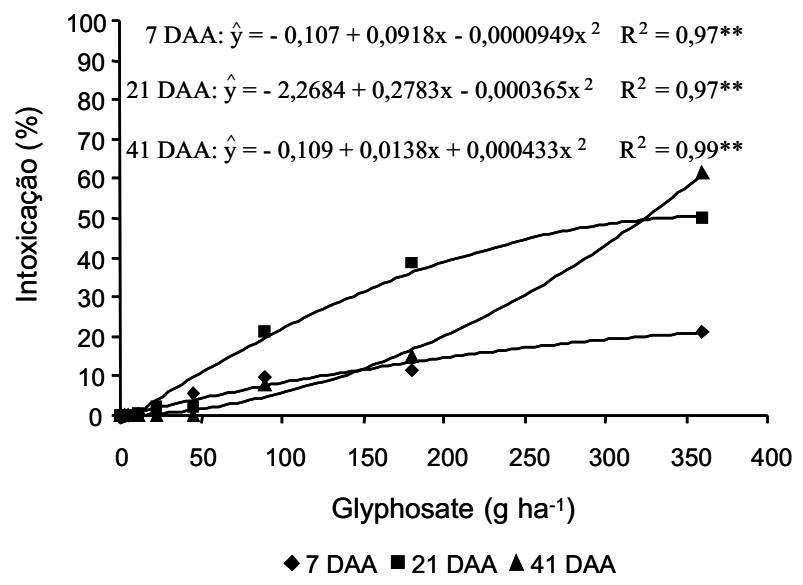

Figura 1 - Porcentagem de intoxicação nas plantas de pinhãomanso submetidas a doses de glyphosate em deriva simulada. 
ápice do caule, e algumas folhas apresentaram coloração púrpura avermelhada. Nos sintomas mais severos de intoxicação, o amarelecimento também foi observado nas folhas da parte basal da planta, seguido de necrose, principalmente das folhas imaturas do ápice do caule. Algumas folhas sofreram abscisão após dois ou três dias do surgimento dos sintomas severos de intoxicação.

Aos 21 DAA, também foram observados na Figura 1 sintomas de intoxicação a partir da dose de $11,3 \mathrm{~g} \mathrm{ha}^{-1}$, com evolução dos sintomas inferior a 2,0\% até a dose de 45,0 $\mathrm{g} \mathrm{ha}^{-1}$. Ocorreu ainda aumento expressivo desses sintomas para as doses de 90,0, 180,0 e $360,0 \mathrm{~g} \mathrm{ha}^{-1}$, que proporcionaram médias em torno de 21,0, 38,7 e 50,0\%, respectivamente. Os sintomas observados em plantas de pinhãomanso expostas às doses de $11,3,22,5 \mathrm{e}$ 45,0 $\mathrm{g} \mathrm{ha}^{-1}$ desapareceram completamente aos 41 DAA (Figura 1). Entretanto, verificou-se que nesse período as plantas de pinhão-manso começaram a apresentar recuperação da coloração normal das folhas e a emitir brotações não viáveis (anormais) para as doses de 90,0, 180,0 e 360,0 $\mathrm{g} \mathrm{ha}^{-1}$.

Santos et al. (2005), trabalhando com simulação de deriva em eucalipto, observaram que o aparecimento dos sintomas se relaciona à quantidade de produto em contato com as plantas e que sintomas caracterizados por necroses e cloroses foliares foram observados a partir do quinto dia após aplicação. Esses pesquisadores observaram recuperação das plantas tratadas com doses de $172,8 \mathrm{~g} \mathrm{ha}^{-1} \mathrm{de}$ glyphosate aos 45 DAA, com emissão de novas brotações, porém com sintomas de intoxicação nas partes mais velhas.

Na Figura 2 encontram-se os resultados referentes ao número de ramos nas plantas de pinhão-manso aos 41 DAA do glyphosate. Observou-se que os dados obtidos não se ajustaram a nenhum modelo de regressão; contudo, esse fato pode ser considerado normal, uma vez que as plantas de pinhão-manso não possuem um padrão definido de arquitetura da parte aérea, além de a emissão de ramos, flores e frutos não ser uniforme (Purcino \& Drummond, 1986; Arruda et al., 2004; Saturnino et al., 2005).

Em relação à testemunha sem aplicação, todas as doses de glyphosate proporcionaram redução na altura da planta; reduções superiores a $7,5 \%$ foram verificadas a partir da dose de 45,0 g ha $^{-1}$ aos 41 DAA (Figura 3). A abscisão foliar, que ocorreu sobretudo no ápice do caule, bem como a presença de brotações não viáveis, pode explicar a redução na altura das plantas de pinhão-manso promovida principalmente pelas maiores doses de glyphosate.

Os resultados referentes ao diâmetro de caule (Figura 4) comportaram-se de maneira semelhante à observada para a altura de planta (Figura 3). As maiores reduções do diâmetro do caule foram proporcionadas pelas doses de 180,0 e 360,0 $\mathrm{g} \mathrm{ha}^{-1}$ de glyphosate, com médias de 10,8 e $31,5 \%$, respectivamente, em relação à testemunha sem aplicação.

Da mesma forma, o aumento das doses de glyphosate proporcionou reduções na área foliar das plantas de pinhão-manso (Figura 5). Observou-se que doses de até $22,5 \mathrm{~g} \mathrm{ha}^{-1}$ de glyphosate promoveram decréscimo da área foliar inferior a 5,7\%, e reduções superiores a

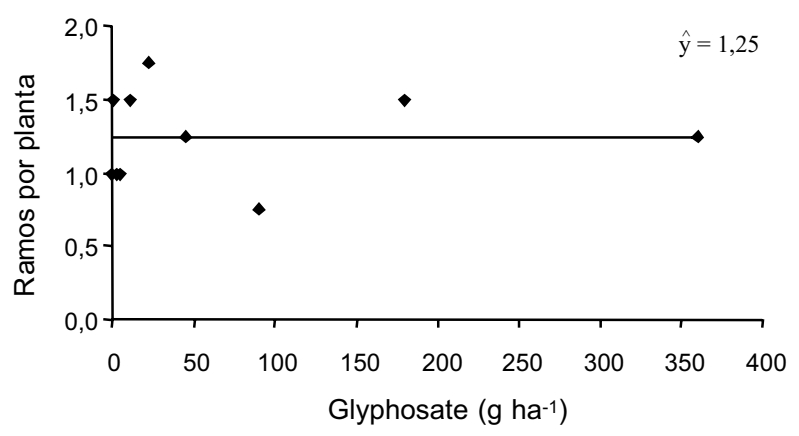

Figura 2 - Número de ramos por planta de pinhão-manso, aos 41 dias após a simulação da deriva de glyphosate.

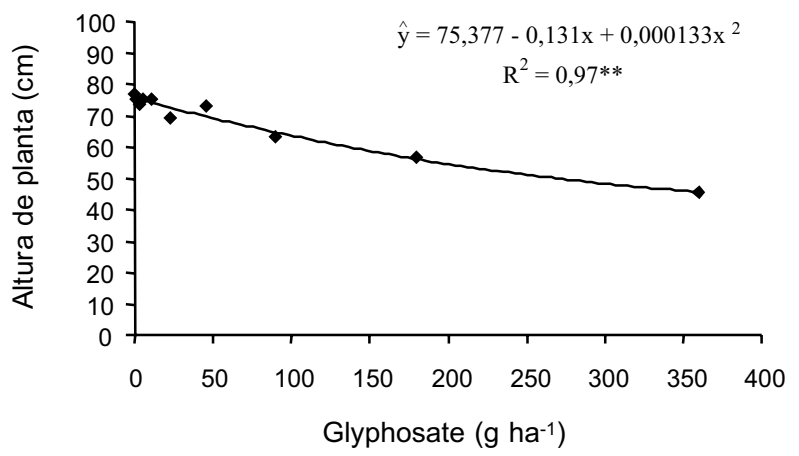

Figura 3 - Altura de plantas de pinhão-manso, aos 41 dias após a simulação da deriva de glyphosate. 


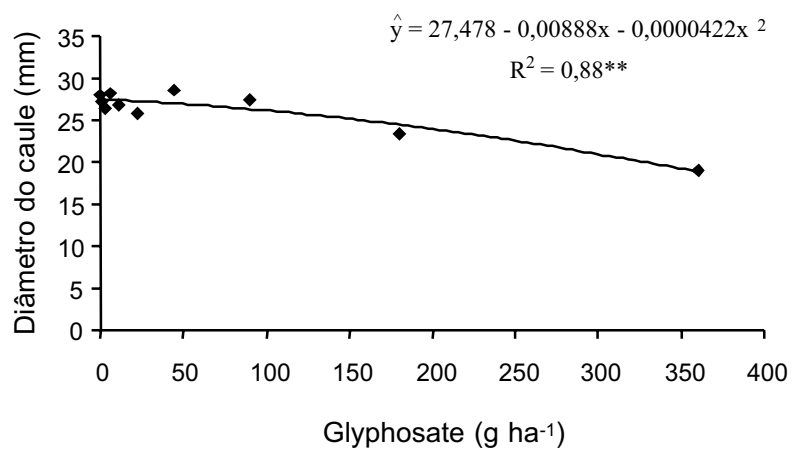

Figura 4 - Diâmetro do caule de plantas de pinhão-manso, aos 41 dias após a simulação da deriva de glyphosate.

$11,3 \%$ ocorreram a partir da dose de 45,0 $\mathrm{g} \mathrm{ha}^{-1}$ de glyphosate, em comparação com a testemunha sem aplicação. No entando, devem-se verificar em novos estudos os efeitos da redução da área foliar de plantas de pinhão-manso devido à deriva de glyphosate sobre o processo fotossintético.

Em estudos com eucalipto, Santos et al. (2005) relatam que a área fotossintética perdida devido a senescência foliar e necroses, causadas pela ação do glyphosate, pode ser compensada com o aumento na espessura e na área proporcional ao parênquima paliçádico do limbo foliar.

Na Figura 6 são apresentados os ajustes obtidos pela análise de regressão das médias de massa seca de folha, caule, raiz e da planta de pinhão-manso, aos 41 DAA do glyphosate. Pode-se verificar que as doses de glyphosate avaliadas influenciaram negativamente o acúmulo de massa seca das plantas de pinhãomanso, e os efeitos mais expressivos ocorreram a partir da dose de 45,0 $\mathrm{g} \mathrm{ha}^{-1}$. Considerando a massa seca da folha, houve decréscimo superior a $12,6 \%$, enquanto para a massa seca do caule e da raiz as reduções foram superiores a 9,7 e 12,1\% a partir das doses de 180,0 e 90,0 $\mathrm{g} \mathrm{ha}^{-1}$, respectivamente, em relação à testemunha sem aplicação (Figura 6).

Desse modo, verificou-se que as folhas das plantas de pinhão-manso foram mais sensiveis à simulação da deriva de glyphosate em relação ao caule e às raízes. Isso pode ser justificado pelo fato de as folhas terem recebido os maiores depósitos de calda no momento da simulação da deriva em relação às demais

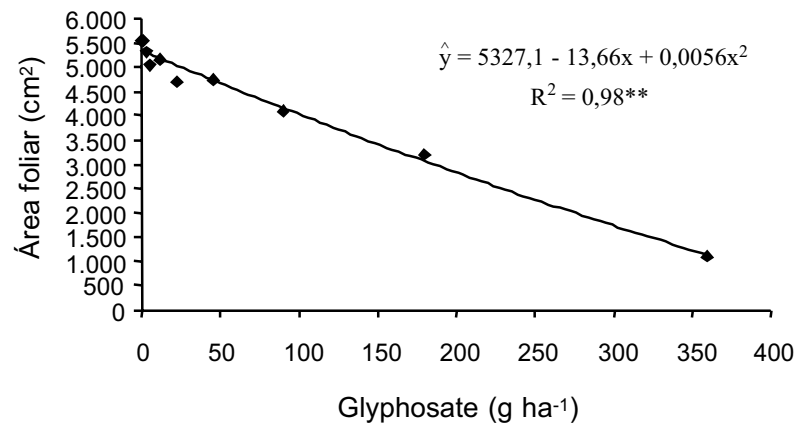

Figura 5 - Área foliar de plantas de pinhão-manso, aos 41 dias após a simulação da deriva de glyphosate.

partes da planta, o que pode ter favorecido a maior absorção do produto. Constatou-se ainda que nenhuma das doses do herbicida estimulou o crescimento das plantas, nas diferentes variáveis avaliadas.

Velini et al. (2008) ressaltam que o glyphosate aplicado em altas doses inibiu o crescimento de espécies não transgênicas, como Glycine max, Zea mays, Commelina benghalensis, Eucalyptus grandis e Pinus caribea. Entretanto, quando aplicado em doses baixas $\left(1,8\right.$ a $\left.36,0 \mathrm{~g} \mathrm{ha}^{-1}\right)$, o glyphosate proporcionou estímulo entre 50 e $100 \%$ no crescimento de folha, caule e raiz, nas espécies C. benghalensis, E. grandis e P. caribea. Da

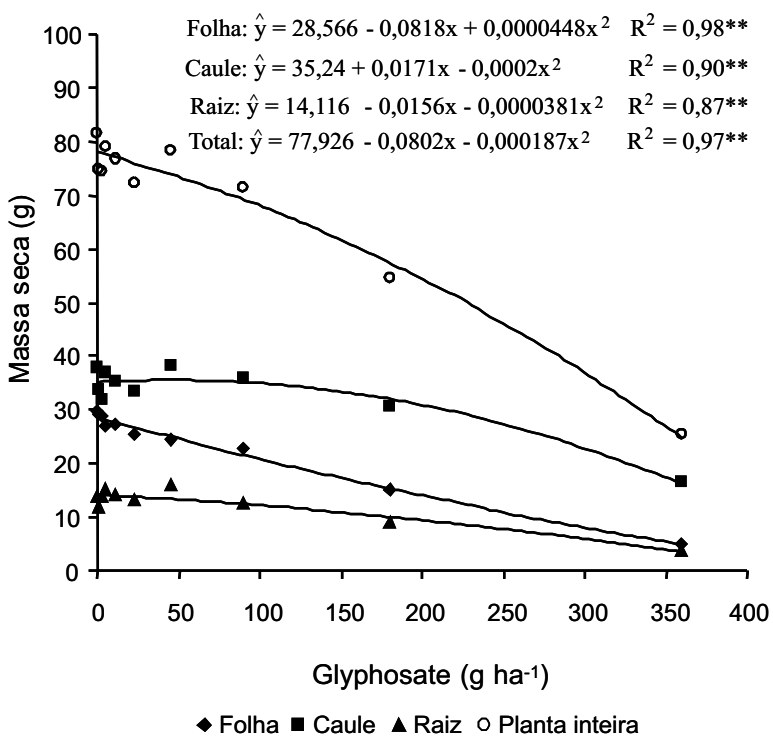

Figura 6 - Massa seca de folha, caule, raiz e da planta de pinhãomanso, aos 41 dias após a simulação da deriva de glyphosate. 
mesma forma, Cedergreen (2008) afirma que o glyphosate pode estimular o acúmulo de biomassa em plantas de Hordeum vulgare em torno de $25 \%$, quando são aplicadas doses que correspondem de 5 a $10 \%$ da dose recomendada.

Ao analisar a massa seca da planta inteira de pinhão-manso nas doses de 45,0, 90,0, 180,0 e 360,0 $\mathrm{g} \mathrm{ha}^{-1}$ de glyphosate, foram observadas reduções de 9,2, 14,9, 28,6 e $65,8 \%$, respectivamente, em relação à testemunha sem aplicação. Para doses menores que $22,5 \mathrm{~g} \mathrm{ha}^{-1}$ de glyphosate, a redução do acúmulo da massa seca da planta inteira foi, em média inferior a $6,7 \%$.

Esses resultados corroboram os obtidos por Santos et al. (2007b), que observaram em plantas de eucalipto com grau de intoxicação por glyphosate entre 21 e 30\% e entre 41 e $50 \%$, comprometimento na produção de madeira de 18 e 48\%, respectivamente, aos 360 DAA, e que a amplitude da redução foi dependente da dose de glyphosate aplicada na planta.

Com base nos resultados, pode-se concluir que as plantas apresentaram boa tolerância à deriva simulada de glyphosate até a dose de $22,5 \mathrm{~g} \mathrm{ha}^{-1}$. Contudo, deriva de doses superiores a $45,0 \mathrm{~g} \mathrm{ha}^{-1}$ desse herbicida pode prejudicar severamente o desenvolvimento inicial das plantas de pinhão-manso.

Dessa forma, ressalta-se a importância da realização de estudos que visem aprimorar a tecnologia de aplicação de herbicidas, de modo a evitar os prejuízos que a deriva da calda pulverizada pode causar sobre o desenvolvimento das plantas. Devem-se avaliar ainda as consequências das aplicações consecutivas por um longo período na mesma área e os possiveis efeitos benéficos que o glyphosate ou outros herbicidas podem proporcionar no crescimento e desenvolvimento das plantas de pinhão-manso.

\section{LITERATURA CITADA}

ARRUDA, F. P. et al. Cultivo do pinhão-manso (Jatropha curcas L..) como alternativa para o semi-árido nordestino. R. Bras. Oleag. Fibrosas, v. 8, n. 1, p. 789-799, 2004.

CEDERGREEN, N. Herbicides can stimulate plant growth. Weed Res., v. 48, n. 5, p. 429-438, 2008

GRAVENA, R. et al. Low glyphosate rates do not affect Citrus limonia (L.) Osbeck seedlings. Pest Manag. Sci., v. 65 , n. 4 , p. $420-425,2009$
POWELL, J. R.; SWANTON, C. J. A critique of studies evaluating glyphosate effects on diseases associated with Fusarium spp. Weed Res., v. 48, n. 4, p. 307-318, 2008.

PURCINO, A. A. C.; DRUMMOND, O. A. Pinhão-manso. Belo Horizonte: EPAMIG, 1986. 7 p

RIZZARDI, M. A. et al. Ação de herbicidas sobre mecanismos de defesa das plantas aos patógenos. Ci. Rural, v. 33, n. 5 , p. $957-965,2003$

RODRIGUES, B. N.; ALMEIDA, F. S. Guia de herbicidas. 5.ed. Londrina: Edição dos Autores, 2005. 592 p.

SANTOS, L. D. T. et al. Crescimento e morfoanatomia foliar de eucalipto sob efeito de deriva do glyphosate. Planta Daninha, v. 23, n. 1, p. 133-142, 2005.

SANTOS, L. D. T. et al. Intoxicação de espécies de eucalipto submetidas à deriva do glyphosate. Planta Daninha, v. 24, n. 2, p. 359-364, 2006.

SANTOS, L. D. T. et al. Crescimento e concentração de nutrientes na parte aérea de eucalipto sob efeito da deriva do glyphosate. Cerne, v. 13, n. 4, p. 347-352, 2007a

SANTOS, L. D. T. et al. Crescimento do eucalipto sob efeito da deriva de glyphosate. Planta Daninha, v. 25, n. 1, p. 133-137, $2007 \mathrm{~b}$.

SANTOS, L. D. T. et al. Danos visuais e anatômicos causados pelo glyphosate em folhas de Eucalyptus grandis. Planta Daninha, v. 26, n. 1, p. 9-16, 2008

SATURNINO, H. M. et al. Cultura do pinhão-manso (Jatrorpha curcas L.). Inf. Agropec., v. 26, n. 229, p. 44-78, 2005.

SEVERINO, L. S.; VALE, L. S.; BELTRÃO. N. E. A simple method for measurement of Jatrorpha curcas leaf area. R. Bras. Oleag. Fibrosas, v. 11, n. 1, p. 9-14, 2007.

SOCIEDADE BRASILEIRA DA CIÊNCIA DAS PLANTAS DANINHAS - SBCPD. Procedimentos para instalação, avaliação e análise de experimentos com herbicidas. Londrina: 1995. 42 p.

TEIXEIRA, L. C. Potencialidades de oleaginosas para produção de biodiesel. Inf. Agropec., v. 26, n. 229, p. 18-27, 2005.

VELINI, E. D. et al. Glyphosate applied at low doses can stimulate plant growth. Pest Manag. Sci., v. 64, n. 4, p. 489-496, 2008.

WAGNER JÚNIOR, A. et al. Deriva simulada de formulações comerciais de glyphosate sobre maracujazeiro amarelo. Planta Daninha, v. 26, n. 3, p. 677-683, 2008.

YAMASHITA, O. M.; GUIMARÃES, S. C. Resposta de cultivares de algodoeiro a subdoses de glyphosate. Planta Daninha, v.23, n. 4, p. 627-633, 2005. 